We hope this information will be useful to others contemplating using these ventilators. We also hope the various manufacturers can agree on some standardization for anti-pollution devices. D.H. Graham, M.D., F.R.C.P.(C), A. Bishop,

Department of Anaesthesia and Precision Instrument Department, St. Paul's Hospital, Vancouver, B.C.

\section{Anaesthetic Scavenging Systems}

\section{Dear Sir,}

Thank you for letting me see the letter from Dr. Graham and Mr. Bishop. They raise two subjects which are only peripherally related.

The modification of their machine to accommodate the ventilator on the bracket of the absorber is not particularly controversial and I presume each anaesthetist will find his own solution when similar problems present themselves.

The various diameters of valves, ports and hoses is quite a different matter, and is one which has engaged the attention of the Committee on Anaesthetic Equipment and Respiratory Technology of the Canadian Standards Association, as well as the Technical Committee on Anaesthetic Equipment of the International Standards Organization, for a number of years. A Standard for scavenging devices, including fittings and hoses, is in the final stages of preparation and any remaining controversial points should be finalized this summer.

Your correspondents do not seem to realize that only by the active concern of consumers through their professional organization, in our case the Canadian Anaesthetists' Society and, through them, in turn, the Canadian Standards Association, can interchangeability between the products of various manufacturers be achieved. Manufacturers themselves are not particularly interested in this subject, unless prodded by the consumer, since differences between them can also be exploited commercially, often to the ultimate detriment of the consumer. Your correspondent should also realize that even with the publication of standards there is no guarantec that manufacturers will conform, as standards themselves do not carry the weight of law. Only the user, by refusing to purchase non-standard equipment, can enforce compliance by manufacturers.

Considerable success has been achieved in standardization of anaesthetic machines, ventilators, gas piping systems, filling devices for liquid anaesthetics, tracheal tubes and connectors and, most recently, oxygen analyzers. Most of the standards have met considerable enthusiasm by the users and, thus, compliance by manufacturers who have cooperated in the writing of these standards. We are anticipating that the scavenging devices standard will be equally well received.

Gordon M. Wyant, M.D., F.R.C.P.(C) Chairman, Technical Committee on Anaesthetic Equipment and Respiratory Technology, Canadian Standards Association.

IntRavenous Regional Bupivacaine WITH a Forearm TOURNIQUET

SIR,

We were very interested to read the article by Drs. Enright, Smith and $W_{y a n t}{ }^{1}$ in which they emphasize the effectiveness and safety of using 0.25 per cent concentration of bupivacaine for intravenous regional anaesthesia. We feel that this method of anaesthesia can be made even safer in forearm and hand surgery by using a tourniquet below the level of the elbow, which permits the use of still smaller volumes of local anaesthetic. We have found that the 0.25 per cent concentration did not always produce complete analgesia. The use of only $10-15 \mathrm{ml}$ of the $0.5 \mathrm{per}$ cent concentration of bupivacaine $(50-75 \mathrm{mg})$, however, did produce very satisfactory analgesia in almost all of the 152 cases we have treated thus far. A few required an additional $3-5 \mathrm{ml}$ of the intravenous bupivacaine before surgical anaesthesia was obtained. No toxic reaction of any nature was noted in any of these cases, even when the tourniquet was released less than 30 minutes after the injection. Despite the general feeling against the efficacy of a forearm tourniquet $^{2,3}$ a good bloodless field was obtained in all except one patient, in whom the method was abandoned. We are convinced that the small dosages of bupivacaine necessary when a fore- 